\title{
Morphological and molecular data of Hepatozoon ursi in two brown bears (Ursus arctos) in Turkey
}

\author{
Muzaffer Akyuz, Ridvan Kirman and Esin Guven
}

Department of Parasitology, Faculty of Veterinary Medicine, Atatürk University, Erzurum, Turkey

\begin{abstract}
Species of Hepatozoon Miller, 1908 are vector-borne parasites that infect domestic and wild animals worldwide. Hepatozoon ursi Kubo, Uni, Agatsuma, Nagataki, Panciera et al., 2008 was reported from bears (Ursidae) in Japan and India. The present study represents the first report of infection with H. ursi in Turkish brown bears (Ursus arctos Linnaeus) by microscopic and molecular analysis. Two dead brown bears were found in Uzundere and Pasinler districts of Erzurum. Blood and visceral organ (spleen and liver) samples were delivered to laboratory by the Nature Conservation and National Parks officers. Detected gamonts were evaluated based on morphological features and confirmed as gamonts of $H$. ursi. The size of gamonts and parasitemia were $8.2 \times 3.5 \mu \mathrm{m}$ $(6.9-8.7 \times 3.0-3.9 \mu \mathrm{m} ; \mathrm{n}=12)$ and $0.6 \%(6 / 1000$ leukocytes), respectively. The blood and visceral organ samples were positive for species of Hepatozoon by PCR targeting partial sequence of $18 \mathrm{~S}$ rDNA. Sequence analysis of newly obtained sequences of $H$. ursi showed $98.8-100 \%$ identity with previously sequenced isolates of $H$. ursi. Sequences of $H$. ursi from Erzurum were identical to each other and showed $100 \%$ identity with isolates of $H$. ursi from ticks Ixodes ricinus (Linnaeus), Rhipicephalus turanicus Pomerantzev and Hyalomma marginatum Koch collected from two brown bears in Turkey (GenBank accession numbers MN463021, MN463022, MN905023). Analysis of partial sequences of the 18S rRNA gene of $H$. ursi showed that Turkish isolates differ in NT substitutions found at three different positions $[72(\mathrm{~A} \rightarrow \mathrm{G}), 537(\mathrm{~A} \rightarrow \mathrm{G})$ and $570(\mathrm{~A} \rightarrow \mathrm{T})]$. This study provides morphological and molecular data of H. ursi infection in brown bears from two districts of Erzurum, Turkey. Further studies are needed to elucidate whether brown bears have any eco-epidemiologic importance in the life cycle of $H$. ursi in wildlife.
\end{abstract}

Keywords: wildlife, hepatozoonosis, Ursidae, PCR

Protists of the genus Hepatozoon Miller, 1908 (Adeleorina: Hepatozoidae) have a heteroxenous life cycle including a haematophageous invertebrate definitive host and a vertebrate intermediate host (Smith 1996). The presence of species of Hepatozoon in domestic and wild mammals, birds, reptiles, and amphibians have been reported worldwide (Smith 1996, Baneth 2011). These parasites were identified in various wild animals worldwide (Uni et al. 2003, Modrý et al. 2017, Lucas da Silva et al. 2018, Nimisha et al. 2019, Otranto et al 2019).

In Turkey, Hepatozoon canis (James, 1905) was reported in foxes (Orkun and Nalbantoglu 2018) and Hepatozoon sp. in rodents (Usluca et al. 2019). There was no report of any Hepatozoon in brown bears until this study. However, DNA of Hepatozoon ursi Kubo, Uni, Agatsuma, Nagataki, Panciera et al., 2008 was found in the ticks Ixodes ricinus (Linnaeus), Rhipicephalus turanicus Pomerantzev and Hyalomma marginatum Koch collected from two brown bears in Turkey. Hepatozoon ursi was described from Japanese black bear (Ursus thibetanus japonicus Schlegel) by Kubo et al. (2008) based on morphological criteria and molecular studies.

In the following years, this species has been reported from black bears in Japan and sloth bears in India (Ikawa et al. 2011, Pawar et al. 2011). In addition, an unidentified species of Hepatozoon in the Hokkaido brown bears ( $U r$ sus arctos yesoensis Lydekker) (Kubo et al. 2010) and a novel Hepatozoon sp. in giant panda (Ailuropoda melanoleuca David) in USA (Yu et al. 2019) were reported. By contrast, species of Hepatozoon were not found in American black bears (Ursus americanus Pallas) in the United States (Crum et al. 1978) and in European brown bears (Ursus arctos Linnaeus) in Sweden (Mörner et al. 2005).

The brown bear ( $U$. arctos) of the Ursidae is the largest carnivore in Turkey and occurs mainly in the Black Sea and Eastern Anatolia regions. The total bear population ranges between 3,400 and 4,000 in Turkey, and most of them occur in Eastern Anatolia (Ambarl1 et al. 2016).

The present study presents the first report of infection with H. ursi in Turkish brown bears (U. arctos) based on microscopical and molecular analysis. 




Fig. 1. Gamonts of Hepatozoon ursi Kubo, Uni, Agatsuma, Nagataki, Panciera et al., 2008 in the cytoplasm of leukocytes; black arrows show the beak-like protrusion.

\section{MATERIALS AND METHODS}

\section{Sample collection}

Two dead brown bears were found in Uzundere and Pasinler districts of Erzurum (40.5363N, 41.5483E, northeastern Turkey) in 2017 and 2018, respectively. EDTA-anticoagulated blood samples and visceral organs were delivered to the Parasitology Laboratory by Nature Conservation and National Parks officers. Blood samples of the first bear (found in Uzundere), and blood and visceral organs (spleen and liver) from the second bear (found in Pasinler) were evaluated. There was no information about the age and sex of the bears.

\section{Microscopical examination}

Thin blood smears were prepared, air-dried, fixed with methanol and stained with Giemsa (5\%). Giemsa-stained blood samples were examined by light microscope and photographed; the size of gamonts was measured using camera system (Nikon Eclipse Ci, Japan). Parasitemia was calculated by counting parasitised leukocytes among 1,000 leukocytes.

\section{Molecular analysis}

DNA extraction was performed from blood (first and second bear) and visceral tissue samples (second bear) by using a commercial DNA extraction kit (G-spin Total DNA Extraction Kit; Intron, Seoul, Korea) according to the manufacturer's instructions. The obtained DNA was stored at $-20^{\circ} \mathrm{C}$ until further use. A target sequence in the nuclear $18 \mathrm{~S}$ rRNA gene was partially amplified by conventional PCR using primers HepF (5'-ATACATGAGCAAAATCTCAAC-3') and HepR (5'-CTTATTATTCCATGCTGCAG-3') (Inokuma et al. 2002). PCR amplification was performed using $2 \times$ PCR master mix solution (i-Taq, Intron Bio Technology, Seongnam, Korea). Sterile DNase-RNase-free water and DNA of Hepatozoon canis (Accession no.: KY247117) were used as negative and positive control, respectively. PCR reactions were performed on a Veriti 96-well Thermal Cycler (Applied Biosystems, California, USA) with the following cycling conditions: $95^{\circ} \mathrm{C}$ for $5 \mathrm{~min}$, followed by 34 cycles of $95^{\circ} \mathrm{C}$ for $30 \mathrm{~s}, 57^{\circ} \mathrm{C}$ for $90 \mathrm{~s}$, and $72^{\circ} \mathrm{C}$ for $90 \mathrm{~s}$, with a final extension of $72{ }^{\circ} \mathrm{C}$ for $5 \mathrm{~min}$. PCR products were analysed using $1.5 \%$ agarose gel electrophoresis, stained with ethidium bromide, and photographed using UV transillumination (Eberhardzell, Germany, Vilber Lourmat, Quantum ST4, 1100). Three of the four positive PCR products with high DNA concentrations were purified using the PureLink quick gel extraction kit (Invitrogen, Carlsbad, CA). Bidirectional sequencing was performed commercially with an ABI PRISM 310 genetic analyser (Applied Biosystems, Foster City, CA) using the ABI PRISM ${ }^{\circ}$ BigDye terminator cycle sequencing kit.

The nucleotide sequences obtained in this study were compared to registered GenBank sequences using basic local alignment search tool (BLAST) (http://www.ncbi.nlm.nih.gov/ BLAST/). Sequences were edited and aligned using Bioedit 7.0 (http://www.mbio.ncsu.edu/BioEdit/bioedit.html) and then assessed visually. The partial $18 \mathrm{~S}$ rRNA gene sequences from this study and sequences from the GenBank database were used to construct a phylogenetic tree by Neighbor-Joining method based on the Kimura 2-parameter model implemented in MEGA X (Kimura 1980, Kumar et al. 2018), with Adelina dimidiata (Schneider, 1875) as an outgroup. Nucleotide sequences of isolates of Hepatozoon ursi obtained from two brown bears were deposited in GenBank under accession numbers MN150504-MN150506. The isolates (accession nos. MN150505 and MN150506) were obtained from different organs of the same brown bear (found in Pasinler) therefore we used only one isolate (accession no. MN150506) for phylogenetic analyses.

\section{RESULTS AND DISCUSSION}

Gamonts within leukocytes in blood samples of two brown bears were identified as Hepatozoon ursi (Fig. 1). The mean size of the gamonts was $8.2 \times 3.5 \mu \mathrm{m}(6.9-8.7 \times$ $3.0-3.9 \mu \mathrm{m} ; \mathrm{n}=12)$ in length and width, and parasitemia was calculated as $0.6 \%(6 / 1000$ leukocytes $)$. We observed beak-like protrusions at one end of the gamonts which are slightly curved in shape (Fig. 1). The morphology of gamonts of $H$. ursi was described by Kubo et al. (2008) and the beak-like protrusion at one end of the slightly curved gamont is remarked as one of the most characteristic morphological features. Excluding the protrusion, the mean size of the gamonts was $10.9 \times 3.3 \mu \mathrm{m}(10.5-11.5 \times 2.9-3.6)$ by Kubo et al. (2008), which was longer than our measurements. The difference in size can be explained by the developmental stages of the measured gamonts, fixation and staining techniques, errors in measurement and strain variation.

Infections with species of Hepatozoon are usually subclinical in most mammalian hosts; only canid and felid species are of veterinary importance (Pawar et al. 2011, Modrý et al. 2017, Yu et al. 2019). High prevalence and low virulence of infection with species of Hepatozoon in bears were reported in some studies (Uni et al. 2003, Kubo et al. 2008, Ikawa et al. 2011, Pawar et al. 2011). In this 


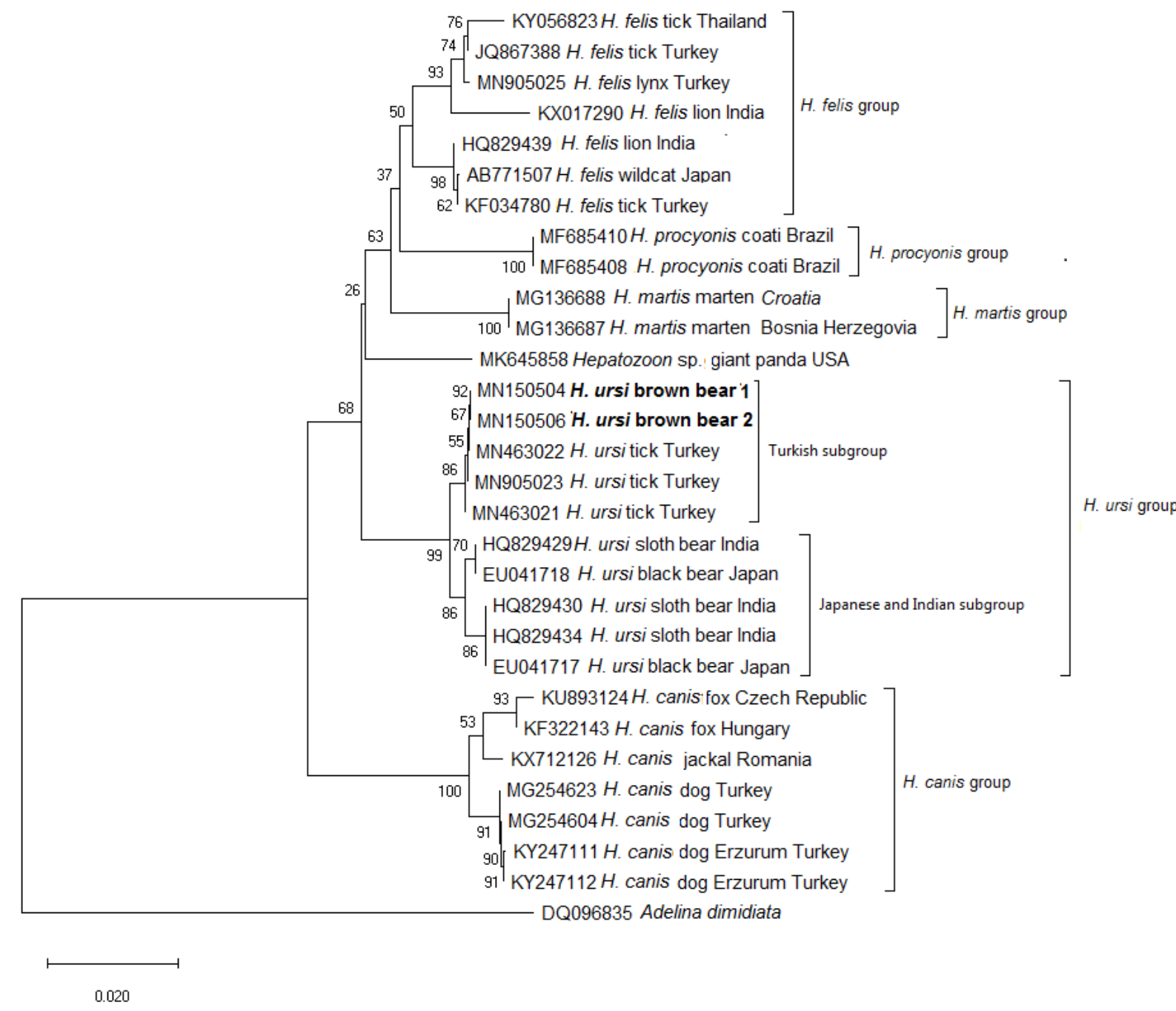

Fig. 2. The phylogenetic tree based on partial sequences (630 bp) of the 18S rRNA gene of species Hepatozoon Miller, 1908, constructed using the neighbor-joining method. Adelina dimidiata (Schneider, 1875) was used as outgroup. New sequences of isolates of H. ursi from this study marked in bold. Numbers on branches indicate bootstrap values based on 1,000 replicates. Scale bar represents 0.02 nucleotide substitutions per site.

study, we could examine only two bears which had low parasitemia $(0.6 \%)$.

PCR amplification was successful and a fragment of approximately $670 \mathrm{bp}$ was amplified from all samples. Sequences of $H$. ursi showed $98.8-100 \%$ identity with isolates of $H$. ursi in the GenBank database. Sequences of $H$. ursi from Erzurum were identical to each other and showed $100 \%$ identity with isolates of $H$. ursi (accession nos. MN463021-MN905023) obtained from tick samples collected from two brown bears in Turkey (Orkun and Emir 2019). Additionally, sequences of Erzurum isolates were very similar ( $99.3 \%$ identity) to those of $H$. ursi isolated from sloth bears (accession nos. HQ829429, HQ829430, HQ829434) in India, and black bears (accession nos. EU041718, EU041718) in Japan.

The phylogenetic tree constructed by Neighbour-Joining method using the partial 18S rRNA gene sequences (630 bp) from this study and 27 isolates of Hepatozoon spp. obtained from GenBank revealed five major groups: H. ursi, Hepatozoon procyonis Richards, 1961, H. felis
(Patton, 1908), H. martis Hodžić, Alić, Beck, Beck, Huber et al., 2018 and H. canis (Fig. 2.). Isolates of H. ursi collected in this study grouped with other isolates of $H$. ursi from other countries. Our isolates constituted a subgroup with isolates of $H$. ursi detected in ticks collected from two brown bears in Turkey, and Japanese and Indian isolates of H. ursi constituted the second subgroup (Fig. 2).

Turkish isolate (accession no. MN150504) was taken as the reference isolate for phylogenetic analyses. One nucleotide (nt) base substitution was found at three different positions $[72(\mathrm{~A} \rightarrow \mathrm{G}), 537(\mathrm{~A} \rightarrow \mathrm{G})$ and $570(\mathrm{~A} \rightarrow \mathrm{T})$ ] at Japanese and Indian isolates compared to the Turkish isolates. Those nucleotide changes in Japanese and Indian isolates of $H$. ursi resulting alteration in deduced amino acid at position $24(\mathrm{I} \rightarrow \mathrm{M})$ and $190(\mathrm{~K} \rightarrow \mathrm{N})$, respectively. The nucleotide change at position 537 caused silent mutation and did not result in the change of the amino acid. The two amino acid differences between Turkish isolates and Japanese-Indian isolates may be the reason of subdivision of the H. ursi group into two subgroups. This remark cer- 
tainly needs to be confirmed with new molecular studies regarding different genes, and new and longer sequences.

This study provides morphological and molecular data of infection with $H$. ursi in brown bears from two distinct regions of Erzurum, Turkey. Further studies are needed to elucidate whether brown bears have any eco-epidemiologic importance in the life cycle of $H$. ursi in wildlife.

\section{REFERENCES}

Ambarli H., Ertürk A., Soyumert A. 2016: Current status, distribution, and conservation of brown bear (Ursidae) and wild canids (gray wolf, golden jackal, and red fox; Canidae) in Turkey. Turk. J. Zool. 40: 944-956.

Baneth G. 2011: Perspectives on canine and feline hepatozoonosis. Vet. Parasitol. 181: 3-11.

Crum J.M., Nettles V.F., Davidson W.R. 1978: Studies on endoparasites of the black bear (Ursus americanus) in the southeastern United States. J. Wildl. Dis. 14: 178-186.

Ikawa K., Aoki M., Ichikawa M., Itagaki T. 2011: The first detection of Babesia species DNA from Japanese blackbears ( $U r$ sus thibetanus japonicus) in Japan. Parasitol. Int. 60: 220-222.

Inokuma H., Okuda M., Ohno K., Shimoda K., Onishi T. 2002: Analysis of the 18S rRNA gene sequence of a Hepatozoon detected in two Japanese dogs. Vet. Parasitol. 106: 265-271.

Kimura M. 1980: A simple method for estimating evolutionary rates of base substitutions through comparative studies of nucleotide sequences. J. Mol. Evol. 16: 111-120.

Kubo M., Chiba E., Iibuchi R., Tsubota T., Sasaki M., Sakai H., Yanai T. 2010: Hepatozoon sp. infection in Hokkaido brown bears (Ursus arctos yesoensis). Jpn. J. Zoo. Wildl. Med. 15: 111113.

Kubo M., Uni S., Agatsuma T., Nagataki M., Panciera R.J., Tsubota T., Nakamura S., Sakai H., Masegi T., Yanai T. 2008: Hepatozoon ursi n. sp. (Apicomplexa: Hepatotoidae) in Japanese black bear (Ursus tibetanus japonicus). Parasitol. Int. 57: 287-294.

Kumar S., Stecher G., Tamura K. 2018: MEGAX: Molecular Evolutionary Genetic Analysis across computing platforms. Mol. Biol. Evol. 35: 1547-1549.

Lucas da Silva M.R., Fornazari F., Martins T.F., Hippólito A.G., Rolim L.S., Bisca J.M., Teixeira C.R., O’Dwyer L.H. 2018: A survey of hemoparasites and ectoparasites in Nasua nasua Linnaeus, 1766 with a redescription of Hepatozoon procyonis Richards, 1961 based on morphological and molecular data. Parasitol. Res. 117: 2159-2169.

Modrý D., Beck R., Hrazdilová K. 2017: A review of methods for detection of Hepatozoon infection in carnivores and arthropod vectors. Vector Borne Zoonotic Dis. 17: 66-72.

Mörner T., Eriksson H., Brojer C., Nilsson K., Uhlhorn H., Agren E., af Segerstad C.H., Jansson D.S., Gavier WidÉN D. 2005: Diseases and mortality in free-ranging brown bear (Ursus arctos), gray wolf (Canis lupus), and wolverine (Gulo gulo) in Sweden. J. Wildl. Dis. 41: 298-303.

Nimisha M.Ç., Devassy J.K., Pradeep R.K., Pakideery V., Sruthi M.K., Pious A., Kurbet P.S., Amrutha B.M., Chandrasekhar L., Deepa C.K., Ajithkumar K.G., Varghese A., Juliet S., Dinesh C.N., Nair S.N., Chandy G., Ghosh S., Ravindran R. 2019: Ticks and accompanying pathogens of domestic and wild animals of Kerala, South India. Exp. Appl. Acarol. 79: 137-155.

ORKun Ö., EMIR H. 2019: Blood-sucking ticks from several wild animals in Turkey and identification of tick-borne pathogens in those ticks: Theileria capreoli, Hepatozoon ursi, and Candidatus Rickettsia barbariae the first reports in Turkey. In: Y. Özbel (Ed.), 21st Parasitology Congress, 28 September-3 October 2019, İzmir, pp. 334

Orkun Ö., NalbantoĞlu S. 2018: Hepatozoon canis in Turkish red foxes and their ticks. Vet. Parasitol. 13: 35-37.

Otranto D., Iatta R., Baneth G., Cavalera M.A., Bianco A., Parisi A., Dantas-Torres F., Colella V., McMilLan-Cole A.C., Chomel B. 2019: High prevalence of vector-borne pathogens in domestic and wild carnivores in Iraq. Acta. Trop. 197: 105058.

Pawar R.M., Poornachandar A., Arun A.S., Manikandana S., Shivaji S. 2011: Molecular prevalence and characterization of Hepatozoon ursi infection in Indian sloth bears (Melursus ursinus). Vet. Parasitol. 182: 329-332.

Sмith T.G. 1996: The genus Hepatozoon (Apicomplexa: Adeleina). J. Parasitol. 82: 565-585.

Uni S., Matsubayashi M., Ikeda E., Suzuki Y. 2003: Characteristics of a hepatozoonosis in lungs of Japanese black bears (Ursus tibetanus japonicus). J. Vet. Med. Sci. 65: 385-388.

Usluca S., Celebi B., Karasartova D., Gureser A.S., Matur F., Oktem M.A., Sozen M., Karatas A., Babur C., MumCUOGLU K.Y., OzKan A.T. 2019: Molecular survey of Babesia microti (Aconoidasida: Piroplasmida) in wild rodents in Turkey. J. Med. Entomol. 56: 1605-1609.

Yu J.H., Durrant K.L., Liu S., Ellen P., Wang C.C., Rodriguez J., Bratthauer A., Walsh T., Valitutto M.T., Fine L., Murray S., Fleischer R.C. 2019: First report of a novel Hepatozoon sp. in giant pandas (Ailuropoda melanoleuca). Ecohealth 16: 338-345. 